\title{
WHATSAPP AS A TOOL FOR SUSTAINABLE GLOCAL LINGUISTIC, SOCIAL AND CULTURAL INTERACTION
}

\author{
Dr. Aysegul TAKKAC TULGAR \\ ORCID: 0000-0001-6401-969X \\ ELT Department, Ataturk University \\ Erzurum, Turkey
}

Received: 22/06/2018 Accepted: 09/08/2018

\begin{abstract}
As a popular social media application, WhatsApp has become an integral part of daily lives of many people on earth. Researchers have investigated the individual, social and pedagogical benefits of the tool. However, the possible contributions of WhatsApp as a platform for cultural interaction in the glocal sense has not been examined yet. To call attention to this dimension of the tool, this case study aims to investigate the role of WhatsApp in maintaining glocal linguistic, social and cultural interaction among a group of foreign learners of Turkish. The participants had a three-week summer school experience in Turkey where they formed a WhatsApp group for communication. After returning back to their home countries, these participants continued their interaction with their friends through the WhatsApp group. The data for this study were collected through open-ended questions. The results of the content analysis revealed that WhatsApp was an effective application to promote the maintenance of glocal cultural interaction among the participants with its personal, social and linguistic contributions. The participants could have the chance to exchange ideas and increase their perspectives and knowledge as global citizens while preserving their cultural and national identities as local citizens. Their interactional experiences through WhatsApp can be said to have helped the participants increase their awareness and expand their intercultural knowledge from the glocal stance.
\end{abstract}

Keywords: WhatsApp, glocal interaction, cultural interaction, foreign learners of Turkish.

\section{INTRODUCTION}

Stunning developments in technology have exerted their influence on different areas of human life including education. As technology has become an integral part of daily life with a growing number of users, it has become inevitable to see the profound effects of technology in the educational arena. Especially considering the recent student profiles whom Prensky (2006) defines as "digital natives" (p.9), teachers have become more willing to benefit from technology in different forms more than ever. Since technological devices, computers and mobile phones in particular, are increasingly utilized as educational tools, the concepts CALL (Computer Assisted Language Learning) and MALL (Mobile Assisted Language Learning) have been introduced in educational field. Within this context, mobile technology is frequently preferred and integrated in the process of education, also covering language education, because of discernible benefits it brings along with itself. Stockwell and Hubbard (2013) point at three main areas of advantage in mobile technology integration: physical advantage referring to the portable nature of mobile devices; pedagogical advantage which is about the dynamic educational interaction between teachers and learners and psychosocial advantage which supports the personal and social interactions of users. In this sense, the social media applications available through smartphones can also be said to offer the above mentioned benefits.

Social media applications, which are defined as "a group of Internet-based applications that build on the ideological and technological foundations of Web 2.0 and that allow the creation and exchange of usergenerated content" (Kaplan \& Haenlin, 2010, p.63), have become popular, especially in the last decade, as tools used among the world citizens for different purposes ranging from social or personal interaction to education. There are various applications with regular users like Facebook, Twitter, Instagram, Blogs, Wikis and WhatsApp. The foremost benefit coming along with these applications is the advantage of skipping time and place limitations (Berge \& Muilenburg, 2013; Ishtawaiwa, 2014; Sundgren, 2017). In other words, these applications enable users to go beyond temporal and contextual boundaries. Regarding mobility and interaction 
as other benefits, $\mathrm{Li}$ (2008) comments that these tools center on "the mobility of the learning practice, and emphasizes the interaction between the learner and the learning content, peers or the instructors" (p.694).

As these tools have become an integral part of education, researchers have focused on diverse issues of investigation regarding the integration of these tools in education: experiences with mobile learning (Harpur, 2017; Menkhoff \& Bengtsson, 2012); factors affecting social media use for pedagogical purposes (Aifan, 2015; Gyamfi, 2017; Ma \& Chan, 2014); the effects of social media on educators (Al-Aufi \& Fulton, 2015; Carpenter $\&$ Green, 2017); attitudes of teachers and students towards social media use (Al-Emran, Elsherif \& Shaalan, 2016); attitudes of teachers towards integrating social media in education (Rezaei \& Meshkatian, 2017); the effects on social media on teacher-student relationship (Gan \& Balakrishnan, 2017) and review studies on the integration of social media (Aydın, 2012; Kukulska-Hulme \& Viberg, 2018). Literature also presents studies conducted specifically on WhatsApp as a frequently-used social media tool. These studies have examined the integration of WhatsApp for academic purposes (Gallardo, Marqués \& Bullen, 2015; So, 2016); WhatsApp as a supporting tool for parents of children with Autism (Cole, Kharwa, Khumalo, Reinle \& Karrim, 2017) and WhatsApp for assessment in language education (Guler, 2017; Samaie, Nejad \& Qaracholloo, 2018).

As understood from the contents of the above-mentioned studies, the integration of different social media applications in personal, social and educational arena reveal the interest of individuals to benefit from the convenience technological developments provide. However, literature lacks research on the use of social media, WhatsApp in particular as a popular internet-based communication tool supporting texting as well as audio and video messages for cultural interaction in the glocal sense. There is no study, known to the researcher examining the adoption of WhatsApp to maintain glocal cultural interaction among language learners. As the world is becoming a global village, it has become a necessity for world citizens to interact with each other through cultural sharing. This need is also felt by language learners who are expected to learn not only the target language but also its culture while still maintaining their national cultural identities. Therefore, this study aims to present a different perspective by examining the maintenance of glocal linguistic, social and cultural interaction of a group of foreign learners of Turkish through WhatsApp as an application that was commonly used by all the participants in the study.

\section{THEORETICAL FRAMEWORK}

This section presents the theoretical background of the adoption of WhatsApp for intercultural interaction in glocal scale.

Social Constructivism: Vygotsky's sociocultural theory of learning suggests that people learn with the help of their engagement in social experiences and interaction. According to Vygotsky (1978), learning is a social activity occurring through social interaction. The rationale in this theory is that cognitive change can be stimulated through social interaction. Therefore, knowledge sharing through reciprocal interactions is considered to play a key role in promoting social knowledge and developing cognition. As Bandura (1977) states, "behavior and complex learning must be explained in terms of a continuous reciprocal interaction of personal environmental determinants" (p. 11). Sharing similar perspectives with Bandura, Vygotsky (1978) proposes that higher levels of functioning are based on interaction between an individual and others and explains:

Every function in the child's cultural development appears twice: first, on the social level, and later, on the individual level; first, between people (interpsychological) and then inside the child (intrapsychological). This applies equally to voluntary attention, to logical memory, and to the formation of concepts. All the higher functions originate as actual relationships between individuals (p. 57).

The objective of social constructivism can be summarized as a form of knowledge sharing which relates "individual and social knowledge to form a potential team knowledge" (Chou, 2005, p.271). Therefore, constructivism can be said to underline the essential nature of collaboration.

Collaborative Learning: Within the concept of Zone of Proximal Development, Vygotsky (1978) proposes that a learning environment promoting collaboration is essential for constructive learning. In this sense, collaborative learning can be considered as a way to meet the demand for social help which is necessary for the transmission of knowledge in a dynamic and constructive process. This type of learning brings the unique characteristics of each learner and centers on their contributions to the process. Swain (1995) notes 
that this form of collaboration promotes natural learning. Collaborative learning encourages learners to share their knowledge and ideas to foster further internalization and creativity. In such a context, learners can be more encouraged to contribute to the process to learn more.

Technology Acceptance Model: Developed by Davis (1989), this model is about how users accept and adopt computer-based technology. The model explains that there are different factors influencing users to decide whether to use the technology or not. Two foremost factors of the model are the Perceived Usefulness, which is the perception of the user regarding the benefits of using the system, and Perceived Ease of Use, which is about easiness of using the system without experiencing physical and cognitive burden (Davis, 1989). This model also holds the view that the attitudes of users towards new systems affect their acceptance of the model.

Based on the above-mentioned theoretical framework, several conclusions can be reached concerning the adoption of WhatsApp in maintaining glocal cultural interaction. From the social-constructivist stance, WhatsApp can be said to offer chances for social interaction to its users through which they can share ideas and experiences in reciprocal relations. Taking collaborative learning into account, users of this application can provide help and scaffold each other in a natural context of interaction. Based on the Technology Acceptance Model, one can observe the huge number of WhatsApp users worldwide and the increase in number day by day.

\section{LITERATURE REVIEW}

Coming along with the constant developments in technology, the integration of social networks in the field of education has attracted growing attention. Therefore, researchers have focused on this aspect from different dimensions. Dividing them according to their focus, this section presents studies on social media applications integrated in education.

The factors affecting social media use for social and pedagogical purposes have been one of the areas of interest among researchers (Asiedu \& Badu, 2018; Briz-Ponce, Pereira, Carvalho, Juanes-Mendez \& GarcíaPenalvo, 2017; Gyamfi, 2017; Ma \& Chan, 2014). Ma and Chan (2014) aimed to examine the factors influencing the online knowledge sharing behaviors of 299 high school students in Hong Kong. The results of the survey revealed that the perceived online attachment motivation and online relationship commitment positively influenced the participants' knowledge sharing decisions. Working with 160 medical students in Portugal, Briz-Ponce, et al. (2017) found that the participants had positive views towards the adoption of mobile technology for educational purposes and the ease of integration was the main effective factor. In Ghanaian context, Gyamfi (2017), as a result of questionnaires, concluded that perceived usefulness and technological complexity were the main factors influencing 254 geography student teachers' acceptance of Web 2.0 technologies. Asiedu and Badu (2018) reported that the factor affecting 204 sociology students' attitudes were chances for keeping in touch and maintaining distance relationships.

Research has also focused on the attitudes and experiences of students and teachers towards the integration of mobile technologies and social media tools (Al-Emran, et al., 2016; Gallardo, et al., 2015; Menkhoff \& Bengtsson, 2012; Rezaei \& Meshkatian, 2017). In a case study design, Menkhoff \& Bengtsson (2012) investigated the pedagogical effects of mobile learning tools in undergraduate courses in China and Singapore. The results showed that communication technologies and social media platforms add pedagogical contributions as they enhanced educational process. Collecting data from 383 students and 54 instructors in five universities in Oman and United Arab Emirates through questionnaires, Al-Emran, et al. (2016) concluded that while the participants held positive attitudes towards mobile technologies; gender, age, smartphone ownership and level of study were the general factors affecting their attitudes. Rezaei and Meshkatian (2017) examined the perceptions of 46 Iranian ELT teachers regarding social media in teaching. The results of the survey pointed at the positive attitudes of the participants and their awareness of the pedagogical benefits of social media in teaching.

Another focus in research was on the effects of social networking tools on the professional practices of teachers (Al-Aufi \& Fulton, 2015; Carpenter \& Green, 2017). In a cross-institutional study, Al-Aufi and Fulton (2015) sent an online questionnaire to 382 academicians in Ireland and Oman. The analysis pointed mainly at the scholarly informal communication as the benefit of networking tools. Reaching 240 teachers from nine countries through an online survey, Carpenter and Green (2017) found that they adopted Voxer, a messaging tool, for professional learning and benefitted from it as educators. 
Literature also presents studies specifically focusing on WhatsApp as a social media application (Aburezeq \& Ishtaiwa, 2013; Malhotra \& Bansal, 2017; Rambe \& Bere, 2013; So, 2016). Investigating the perceptions of pre-service language teachers regarding the effect of WhatsApp on their instructional interaction in the United Arab Emirates, Aburezeq and Ishtaiwa (2013) concluded, from the analysis of interviews and WhatsApp posts, that WhatsApp positively affected teacher-student and student-student relationship and enriched instructional content. Conducting in-depth interviews with 20 university students in Catalonia, Gallardo, et al. (2015) examined the digital technology adoption in their social and academic lives. The results revealed that WhatsApp was the most frequently used tool as it enabled the participants to have easy contact and communication and share social and pedagogical interests with others. Conducting a case study with 95 undergraduates in a South African university, Rambe and Bere (2013) reported that WhatsApp had the potential to promote education offering chances for student collaboration. In an experimental study with 61 undergraduate students in Hong Kong, So (2016) investigated the use of WhatsApp to support education. The intervention of WhatsApp in offering additional materials and further teacher-student interaction was observed to positively affect the perceptions of the participants and their learning. Examining the level of adoption of WhatsApp for academic purposes by 100 post-graduate and 100 undergraduate students in India, Malhotra and Bansal (2017) concluded from the results of the questionnaire that post-graduate students were using the application for academic purposes more than the undergraduate students. Examining the benefits of WhatsApp from a different perspective, Cole, et al. (2017) carried out a phenomenological study with parents of children with Autism. The results of the interviews with six participants revealed the additional support for these parents provided through their WhatsApp groups.

WhatsApp was examined also as a source of assessment in education (Guler, 2017; Samaie, et al., 2018). Working with two groups of undergraduates in Turkish context, Guler (2017) aimed to examine WhatsApp as a tool for peer assessment. The researcher noted that WhatsApp was a valid tool for peer assessment and the participants had positive attitudes towards the application. Samaie, et al. (2018) collected data through think-aloud protocols, questionnaire and interviews to investigate the adoption of WhatsApp as a tool for self and peer assessment by 30 Iranian learners of English. Unlike the ones in Guler's (2017) study, the results pointed at the negative attitudes of the participants towards WhatsApp as an assessment tool.

There are also some studies, though not many in number, evaluating the social network tools in terms of intercultural communication. Researchers considering Second Life as a virtual learning environment stated that this application can foster intercultural literacy and increase the cultural awareness and competence of users (Diehl, 2008; Wang, Song, Stone \& Yan, 2011). As Internet based tools, blogs were also referred to contribute to intercultural competence and enhance intercultural interaction (Hauck \& Youngs, 2008; Lee, 2011, 2012).

In the light of these studies, it can be concluded that social networks have attracted attention as personal, social and pedagogical tools as they offer opportunities for easy access, communication and sharing. Though literature presents studies on the contributions of these networks in terms of providing interactional and intercultural communication, there is a gap in literature regarding research on the adoption of these networks for intercultural interaction from glocal perspective. Therefore, this study is purposed to offer a new perspective focusing on the maintenance of glocal interaction through WhatsApp.

\section{GLOCAL INTERACTION}

In the modern world, globalization holds a significant place in the discussion of many issues ranging from economy to international trade, from politics to tourism and from science to education. In this context, the underlying reason for the essential place of globalization can be said to be the interdependence of all world nations. Especially with the help of technological advancements, the world has become a global village in which world citizens can have closer ties in economic, social, cultural and educational arena (Juergensmeyer, 2013). Yet, a closer examination of this global interconnectedness reveals that there is an unbreakable unity between what is global and local. In this sense, the concept glocal has been introduced to refer to the unity of local with global which can be considered as a combination of locals because it naturally includes what is local, regional and national (You, Kim \& Lim, 2016). Therefore, in glocal context, people with different backgrounds are expected to share their local values to contribute to the richness of the global whole, which is called glocalization. Glocalization appeared as a concept related to global localization, local conditions and farming techniques in Japan (Robertson, 1995). In time it has started to gain relevance in other fields of human life. When education is the case, it entails the conceptualization of the learning environment to include a sociocultural 
framework representing the co-existence of individuals from different nations, cultures, religions and ways of life. Formal education can be seen as becoming increasingly glocalized (Willems \& Bossu, 2012) with the internationalization of higher education in certain countries of the world. In countries where glocalization in higher education is taken seriously, universities have begun to be seen as spearheads of glocalization (Ross \& Lou, 2005). Glocalization is also examined in language and education (Joseph \& Ramani, 2012).

Educational settings, especially universities hosting international students coming from different countries, are ideal spaces for glocal sharing and interaction. Students following their undergraduate or graduate studies in these institutions are forming a glocal atmosphere in which they can learn about different cultures, develop their linguistic knowledge and develop themselves as social beings. The glocal stance enables them to share an international environment while preserving their national, linguistic and cultural identities. When educational institutions are considered through glocal sense, the importance of the cultural dimension becomes more apparent (Khondker, 2013).

\section{METHODOLOGY}

This study adopted exploratory case study design (Yin, 2014) with an aim to examine the effectiveness of WhatsApp for the maintenance of glocal cultural interaction. This design promoted an in-depth understanding of participants' experiences (Bogdan \& Biklen, 2007) and it served for the purposes of further investigation on the issue under discussion. Therefore, through exploratory case study design, this research was intended to examine glocal linguistic, social and cultural interaction through WhatsApp as the medium of glocal interaction in this study because it was the particular social media tool that was commonly used by all participants.

\section{Participants and Research Context}

The participants were twelve foreign learners of Turkish from five different countries (Iran, Kosovo, Azerbaijan, Algeria and Egypt). These participants had a three-week summer school experience in Turkey and were engaged with the target culture and the cultures of other participating friends while continuing their language education. In such a context, they had the chance to be exposed to the target culture and to the cultures of the other participants and to introduce their own culture at the same time. In this way, they contributed to the formation and maintenance of glocal interaction.

During the period these participants were in the host city, a WhatsApp group was formed to maintain contact between the guest students and the host institution. The group involved the students, the instructors giving language lessons in the summer school, the director and the vice director of the institution (who was also the researcher). When the guest students turned back to their home countries, the WhatsApp group still remained active for future interaction among the students and the instructors in the host country. The interactions through the WhatsApp were based on the daily dialogues initiated either by the students or the instructors or on some instances of remembering the memories collected in their visit to the host country. Therefore, this study is based on the experiences of the participants regarding glocal cultural interaction through WhatsApp.

\section{Data Collection Tool}

The data in this study were obtained through the participants' written answers to open-ended questions. The questions were formed by the researcher in light of the casual conversations with the participants through WhatsApp. The open-ended questions were as follows:

1. What are the contributions of the interaction through the WhatsApp group to your language development?

2. What are the contributions of the interaction through the WhatsApp group to your personal development?

3. What are the contributions of the interaction through the WhatsApp group to your social development?

4. What are the contributions of the interaction through the WhatsApp group to your intercultural knowledge and development?

5. What are the contributions of the interaction through the WhatsApp group to your glocal interaction? 
These questions were prepared in Turkish as it is the target language for the participants. Two field experts (one language expert and one expert on teaching Turkish as a foreign language) were consulted in this process to increase the clarity and understandability of the questions to ensure the reliability of the instrument.

\section{Data Collection and Analysis}

Before data collection, informed consent was obtained from all individual participants included in the study. After sending their consent forms to the researcher, the participants received the open-ended questions again through their mails. As all were at $\mathrm{C} 1$ level of language proficiency in Turkish, they were asked to provide answers in the target language, Turkish. Since they were regularly and actively using the WhatsApp group for almost nine months, they were expected to reflect their perceptions regarding their experiences in this period.

Because the answers to the open-ended questions were in Turkish, the researcher translated the comments into English. To increase the reliability of the data, a native speaker did the proofreading of the translations.

Content analysis was adopted to analyze the data. Recurring codes were identified out of the comments of each participant. These codes were cross-checked among all participants' answers in order to ensure the reliability of the analysis, revealing similar codes for each participant. Again to increase reliability of the analysis through interrater reliability, a second rater was also consulted to conduct content analysis. The Internal Rate of Return (IRR) was $82.5 \%$ for exact, $14.5 \%$ for similar and 3\% for different coding, increasing the reliability of the analysis process.

\section{RESULTS}

This section presents the results obtained from the participants' written answers to open-ended questions. The results are presented based on the open-ended questions: the contributions of the WhatsApp group to linguistic development; the contributions of the WhatsApp group to personal and social development; the contributions of the WhatsApp group to intercultural development and the contributions of the WhatsApp group to glocal interaction

\section{The Contributions of the WhatsApp Group to Linguistic Development}

There was a consensus among the written answers of the participants regarding the linguistic gains they obtained through their interactions in the WhatsApp group. They favored the maintenance of the interaction with the help of this application in terms of their language practice. As they were living in different countries in which Turkish is not the native language, they appreciated the available chances for being exposed to the language through the writings and sharing of their group friends as expressed in the below quote:

"I really like this WhatsApp group. As we are using Turkish as the medium of communication in the group, this is an enjoyable way of being exposed to the target language."

The participants also considered the opportunities for practicing the language in the written version as an advantage for their language development. A participant stated that it was like hitting two birds with one stone; they could keep in touch with each other while practicing the language at the same time:

"This group has two main advantages, I think. We can communicate with each other and we can practice the language simultaneously. So, with single effort, we have two gains."

\section{The Contributions of the WhatsApp Group to Personal and Social Development}

The sense of belonging was the underlying reason why all the participants considered the WhatsApp group as contributory. They expressed that they were feeling themselves more comfortable because they knew they had friends around the world with whom they could share their joy and sadness as put forward in the below comment:

"I know that I have friends from Kosovo, Azerbaijan, Algeria and Egypt. Though I may not see them in person in my future life, I believe that we can be in contact throughout our lives with the help of this WhatsApp group. Being part of this group makes me feel contended." 
The sense of belonging and sharing was also reported to increase the confidence of the participants. More than half of the participants noted that they had more confidence in themselves seeing that they could be a part of the group about whom other group members cared. The sense of being valued increased the selfconfidence of the participants as social beings:

"There is an observable increase in my self-confidence with this group. I have realized that I am an important member of the group and that my friends care for me. This really makes me happy and increases my confidence."

\section{The Contributions of the WhatsApp Group to Intercultural Development}

As the participants were in constant contact with each other in the group, they were sharing cultural aspects besides their personal experiences. They were, for example, sharing some events taking place on their national days, some occasions peculiar to their culture and history or sometimes important social or political developments in their countries. All these sharings were reported to contribute to the intercultural knowledge and understanding of the participants. The lack of chance to have face-to-face contact with each other did not block the participants from receiving news about each other and the events in their countries. This chance of social and intercultural contact increased the awareness and knowledge base from the intercultural perspective as reflected by a participant:

"In this WhatsApp group, there are many things we talk about including events peculiar to our own cultures. In this way, I can obtain more detailed knowledge of the cultural or national aspects in my friends' countries. I think this is a great chance for us because the cultural information is directly coming to us without much effort to search for it."

The chance of sharing one's cultural aspects was also regarded as an activity favored by the participants. The group provided the participants with the chance to share their own culture as well as learning about the others'. While increasing their intercultural knowledge, the participants could also reflect their national, historical and cultural peculiarities preserving their national and cultural identities. This was reported to increase the motivation of the participants in contributing to the group interaction:

"The WhatsApp group helps us in two ways: we can learn about other cultures and we can share our culture with them. To me, this is an easy and effective way to develop our intercultural knowledge while maintaining our cultural identity at the same time. I believe this is the exact way of intercultural sharing."

\section{The Contributions of the WhatsApp Group to Glocal Interaction}

As also reflected in the above-mentioned comments, the WhatsApp group enabled the participants to have social and cultural sharings with each other without imposing them the social lives and cultures of other nations. The participants experienced the sense of glocal interaction in a relaxing and motivating atmosphere in which they could increase their intercultural repertoire and could preserve their own cultural identities as stated in the below quote:

"I enjoy this group because of two main reasons. First, it offers us easy contact with our friends and we learn about their national and cultural values through regular sharings. Second, while being aware of intercultural information, we can still be ourselves keeping and sharing our own national and cultural characteristics. We are not forced to change; instead, we are encouraged to develop our intercultural knowledge while maintaining our own cultural identity."

In these group interactions, the participants were not just exposed to the information coming from their peers, which can be considered as a source of global information; they were also contributing to discussions, which is a source of local information. Therefore, the WhatsApp group offered a combination of global and local sharing, promoting glocal interaction among the participants. Appreciating the combination of two knowledge sources, a participant expressed that the content of the group sharings were motivating her to learn more about her own culture to share particulars of her culture with her friends:

"Personal, social and cultural issues constitute a large part of the content of the group sharings. As regards cultural sharing, I really want to participate in the interaction and reflect elements in my local and national culture. So, I sometimes find myself searching for the details of my own culture. I can say that this WhatsApp group increases not just my intercultural knowledge but my knowledge regarding my own culture." 
Besides communicating with their friends from different countries, the participants were also in touch with their instructors in Turkey. Being in contact with the instructors in Turkey provided the participants with the chance to receive and learn information about the target culture as well. As they were learners of Turkish, increasing their knowledge of Turkish culture was also a significant aim for these participants. Considering group interactions from this perspective, a participant expressed his thoughts with the following words:

"I believe, as learners of Turkish, we should also know about the target culture. The WhatsApp group helps us to learn more about the target culture because we are still in contact with the instructors in the host country and this is an opportunity for us not only to develop our language but to expand our cultural knowledge as well."

All in all, these interactions actualized through WhatsApp can be said to be a source of maintaining glocal cultural interaction among the participants. In this atmosphere, the participants experienced the advantage of being in constant contact with their friends. This group helped them share both a social environment with their friends and the possibility to be aware of intercultural events. They also had the chance of sharing their cultural peculiarities, which increased their motivation to participate in group interactions. In this way, the participants could reach increased levels of awareness regarding their own culture, target culture and cultures of other nations and enhance their intercultural knowledge through their glocal cultural interactions in WhatsApp.

\section{DISCUSSION AND CONCLUSION}

Several conclusions can be drawn from the maintenance of glocal linguistic, social and cultural interaction through WhatsApp. These conclusions relate with the linguistic, personal and social development of the participants and the available chances they contribute to the glocal interaction to occur through this Internet tool.

The first conclusion is about the linguistic benefits of the group interactions. As language learning is a dynamic process requiring constant exposure and practice, the WhatsApp group, with its easy access, can be said to offer the participants ample chances of exposure and practice in the target language. Living in foreign contexts in which practice in the target language may not be so available (Lee, 2016), the participants could still continue practicing the target language through this tool. Considered from the social-constructivist and collaborative learning stance, there seems a connection between the linguistic development of the participants in this study and their interactions through WhatsApp. The more they interacted with each other, the more frequently they needed to use the target language. In this case, while they developed their own knowledge and competence in the target language, they also contributed to each other's knowledge and competence.

The second conclusion is related to the personal and social development of the participants. They referred to a sense of belonging experienced through their membership in the WhatsApp group. This sense of belonging was observed to increase the self-confidence of the participants as precious individuals and to increase their motivation as they wanted to contribute to the group more with their experiences and knowledge. Similar results were also reported by Kaliisa and Picard (2017) and Samaie, et al. (2018) noting that communication among students and instructors increased the participants' willingness to participate and engage in the interactions with increased sense of emotional and social presence. Setting out from this perspective, social connectivity (Klopfer, Squire \& Jenkins, 2002) and perceived relationship commitment (Ma \& Chan, 2014) can be evaluated as factors affecting the sense of belonging to such interactional groups. This social connectivity and perceived relationship can also be concluded to be a reflection of the social constructivist mind in that social constructivism suggests the interaction of people to promote learning.

The third conclusion has to do with intercultural development through the WhatsApp group. As the participants were from different countries, they had different linguistic, historical, social and cultural values shaping their beliefs and life styles. WhatsApp was appreciated as a tool for intercultural development as it enabled the participants to learn new things about the cultures of their friends along with the target culture. With the help of easy access to interaction, the participants could go beyond the limits of physical constraints and time limitations, which were reported as advantages also in previous studies (Miller \& Doering, 2014). The participants in this study increased their cultural awareness and competence through intercultural interaction as those participants in previous studies did (Diehl, 2008; Lee, 2011, 2012; Wang, et al., 2011). Since the WhatsApp group provided them with the chance to communicate with their new friends, express 
their ideas and exchange knowledge (Aburezeq \& Ishtaiwa, 2013), the participants could benefit from the advantages of this platform that facilitated glocal interaction. Seo (2013) and Rambe and Bere (2013) also noted that participating in these groups can help people increase their cultural awareness and expand their knowledge through collaborative learning. This intercultural interaction among the participants was also in line with the social constructivist perspective and glocal viewpoint since they were engaged themselves in a collaborative atmosphere in which they helped each other develop their cultural understanding in the global sense while preserving their cultural identities with increasing world knowledge in the local sense.

Taking into account the fact that the participants could share their cultural peculiarities with their friends and learn about their cultural aspects, it can be concluded that the WhatsApp group served as a platform for socializing with the world. The participants were able to reflect their individual, social and cultural presence in this interactive atmosphere. They expanded their knowledge regarding cultural issues in different parts of the world as global citizens and preserved and reflected their national and cultural values as local citizens.

To conclude, citizens in the modern world are expected to keep pace with the constantly developing technologies and to integrate technological tools into their daily lives. As the world is continuously evolving and improving, people should leave the old way behind (Palvik, 2015) and follow what is modern to maintain their glocal presence. Therefore, considering the present case also from the Technology Acceptance Model, it can be suggested that WhatsApp, as a commonly used popular application, can be utilized as a platform for glocal linguistic, social and cultural interaction. As this tool offers its users the chance for time and context-free interaction with worldwide access, world citizens can make use of this application as a way to have contact with other people from different nations. In this way, people can have social and cultural exchanges with each other while keeping their national and cultural values and their identities. Such intercultural interactions can promote the maintenance of glocalization with the presence of local identities having a global mindset.

This study is not out of limitations, the number of the participants ranking first. Another limitation is related to the data collection tool. The data in this study were collected through open-ended questions. For data triangulation, future studies can adopt different data collection instruments and work with more participants.

Setting out from the conclusions of this exploratory case study, future research on the adoption of WhatsApp as a tool for glocal interaction on a linguistic, social and cultural stance can be conducted with different learner groups. This study was conducted with foreign learners of Turkish. Future research can investigate the possible contributions of WhatsApp interactions among learners of different languages. In addition, developing a survey to examine the adoption of social media with a focus on glocal interaction can contribute to the literature.

\section{BIODATA and CONTACT ADDRESSES of AUTHOR}

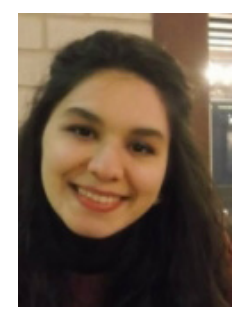

Dr. Aysegul TAKKAC TULGAR, is an assistant professor in ELT Department, Ataturk University, Turkey. She completed her undergraduate education at Middle East Technical University, M.A. and PhD. at Ataturk University. She is currently the vice-director of ATATOMER (Teaching Turkish Center). Her research interests are cross-cultural pragmatic competence, peace education, glocalization and language education.

\section{Aysegul TAKKAC TULGAR}

Address: English Language Teaching Department, Faculty of Education, Ataturk University, 25240, Erzurum, TURKEY

Phone: +904422314244

Email: aysegultakkac@hotmail.com 


\section{REFERENCES}

Aburezeq, I., \& Ishtaiwa, F. (2013). The impact of Whatsapp on interaction in an Arabic language teaching course. International Journal of Arts \& Sciences,6(3), 165-180.

Aifan, H. (2015). Saudi students' attitudes toward using social media to support learning. (Unpublished doctoral dissertation). King Abdu-Aziz University, Jeddah.

Al-Aufi, A., \& Fulton, C. (2015). Impact of social networking tools on scholarly communication: a cross-institutional study. The Electronic Library, 33(2), 224-241, https://doi.org/10.1108/ EL-05-20130093.

Aljomaa, S., Al.Qudah, M., Albursan, I., Bakhiet, S. \& Abduljabbar, A. (2016). Smartphone addiction among university students in the light of some Variables. Computers in Human Behavior, 61, 155164. http://dx.doi.org/10.1016/j.chb.2016.03.041

Al-Emran, M., Elsherif, H., \& Shaalan, K. (2016). Investigating attitudes towards the use of mobile learning in higher education. Computers in Human Behavior, 56, 93-102. http://dx.doi.org/10.1016/j. chb.2015.11.033.

Asiedu, N., \& Badu, E. (2018). Motivating issues affecting students' use of social media sites in Ghanaian tertiary institutions. Library Hi Tech, 36(1), 167-179, https:// doi.org/10.1108/LHT-10-2016-0108.

Aydın, S. (2012). A review of research on Facebook as an educational environment. Educational Technology Research and Development, 60(6), 2093-1106. doi:10.1007/s11423-012-9260-7.

Bandura, A. (1977). Social Learning Theory. New York: General Learning Press.

Berge, Z. L., \& Muilenburg, L. Y. (Eds.). (2013). Handbook of mobile learning. New York: Routledge.

Bogdan, Robert C., \& Biklen, Sari K. (2007). Qualitative Research for Education: An Introduction to Theory and Methods (5th Edition). Boston: Pearson Education, Inc.

Briz-Ponce, L., Pereira, A., Carvalho, L., Juanes-Mendez, J., \& García-Penalvo, F. (2017). Learning with mobile Technologies-Students' behavior. Computers in Human Behavior, 72, 612-620. http://dx. doi.org/10.1016/j.chb.2016.05.027.

Carpenter, J., \& Green, T. (2017). Mobile instant messaging for professional learning: Educators' perspectives on and uses of Voxer. Teaching and Teacher Education, 68, 53-67. http://dx.doi.org/10.1016/j. tate.2017.08.008.

Chou, S. W. (2005). Designing good institutional contexts for innovation in a technology-mediated learning environment. Journal of Computer Assisted Learning, 21(4), 269-280.

Cole, L. Kharwa, Y., Khumalo, N., Reinke, J., \& Karrim, S. (2017). Caregivers of school-aged children with autism: Social media as a source of support. Journal of Child and Family Studies, 26, 3464-3475. doi:10.1007/s10826-017-0855-9.

Davis, F. D. (1989). Perceived usefulness, perceive ease of use, and user acceptance of information technologies. MIS Quarterly, 13(3), 319-340.

Diehl, W. C., \& Prins, E. (2008). Unintended outcomes in Second Life: intercultural literacy and cultural identity in a virtual world. Language and Intercultural Communication 8(2), 101-118. doi:10.1080/14708470802139619.

Gallardo, E., Marqués, L., \& Bullen, M. (2015). Students in higher education: Social and academic uses of digital technology. RUSC. Universities and Knowledge Society Journal, 12(1). pp. 25-37. doi http:// dx.doi.org/10.7238/rusc.v12i1.2078

Gan, C., \& Balakrishnan, V. (2017). Enhancing classroom interaction via IMMAP - An Interactive Mobile Messaging App. Telematics and Informatics 34, 230-243. http://dx.doi.org/10.1016/j. tele.2016.05.007.

Gokcearslan, S., Kus , F., Mumcu, K., Haslaman, T., \& Cevik, Y. (2016). Modelling smartphone addiction: The role of smartphone usage, selfregulation, general self-efficacy and cyberloafing in university students. Computers in Human Behavior, 63, 639-649. http://dx.doi.org/10.1016/j. chb.2016.05.091. 
Gupta, V., \& Jain, N. (2017). Harnessing information and communication technologies for effective knowledge creation: Shaping the future of education. Journal of Enterprise Information Management, 30(5), 831-855. https://doi.org/10.1108/JEIM-10-2016-0173.

Guler, C. (2017). Use of WhatsApp in higher education: What's up with assessing peers anonymously? Journal of Educational Computing Research, 55(2), 272-289.

Gyamfi, S. (2017). Informal tools in formal context: Adoption of web 2.0 technologies among geography student teachers in Ghana. International Journal of Education and Development using Information and Communication Technology, 13(3), 24-40.

Harpur, P. (2017). Mobile lecturers, mobile students: an exploratory study in a blended architectural technology context. Journal of Enterprise Information Management, 30(5), 748-778, https://doi. org/10.1108/JEIM-06-2016-0118.

Hauck, M., Youngs, B. L. (2008). Telecollaboration in multimodal environemnts: The impact on task design and learner interaction. Computer Assisted Language Learning, 21(2), 87-124.

Hedges, S., Odom, S., Hume, K., \& Sam, A. (2018). Technology use as a support tool by secondary students with autism. Autism, 22(1) 70-79. doi:10.1177/1362361317717976.

Joseph M., \& Ramani, E. (2012). "Glocalization": Going Beyond the Dichotomy of Global Versus Local Through Additive Multilingualism. International Multilingual Research Journal, 6(1), 22-34. DOI: $10.1080 / 19313152.2012 .639246$.

Juergensmeyer, M. (2013). What is global studies? Globalizations, 10(6), 765-769. doi: $10.1080 / 14747731.2013 .845956$.

Kaliisa, R., \& Picard, M. (2017). A systematic review on mobile learning in higher education: The African perspective. TOJET: The Turkish Online Journal of Educational Technology, 16(1), 1-18.

Kaplan, A. M., \& Haenlein, M. (2010). Users of the world, unite! The challenges and opportunities of social media. Business Horizons, 53(1). 59-68. doi:10.1016/j.bushor.2009.09.003.

Khondker, H. (2013). Globalization, glocalization, or global studies: What's in a name? Globalizations, 10(4), 527-531. doi: 10.1080/14747731.2013.806747.

Klopfer, E., Squire, K., \& Jenkins, H. (2002). Environment detectives: PDAs as a window into a virtual simulated world. Proceedings of IEEE International Workshop on Wireless and Mobile Technologies in Education (pp. 95-98). Vaxjo, Sweden: IEEE Computer Society.

Kukulska-Hulme, A., \& Viberg, O. (2018). Mobile collaborative language learning: State of the art. British Journal of Educational Technology, 49(2), 207-218. doi:10.1111/bjet.12580

Lee, E. (2016). Advanced ESL students' prior EFL education and their perceptions of oral corrective feedback. Journal of International Students, 6(3), 798-816.

Lee, L. (2011). Blogging: Promoting learner autonomy and intercultural competence through study abroad. Language Learning \& Technology, 15(3), 87-109.

Lee, L. (2012). Engaging study abroad students in intercultural learning through blogging and ethnographic interviews. Foreign Language Annals, 45(1), 7-21.

Li, Q. (2008). "Mobile enhanced learning application model and practice. Computer Society: International Conference on Computer Science and Software Engineering, 694-697.

Ma, W., \& Chan, A. (2014). Knowledge sharing and social media: Altruism, perceived online attachment motivation, and perceived online relationship commitment. Computers in Human Behavior, 39, 51-58. http://dx.doi.org/10.1016/j.chb.2014.06.015.

Malhotra, D., \& Bansal, S.(2017). Magnetism of WhatsApp among veterinary students. The Electronic Library, 35(6), 1259-1267. https://doi.org/10.1108/EL-04-2016-0086.

Menkhoff, T., \& Bengtsson, M. (2012). Engaging students in higher education through mobile learning: lessons learnt in a Chinese entrepreneurship course. Educional Research for Policy Practice, 11, 225242. doi:10.1007/s10671-011-9123-8. 
Miller, C., \& Doering, A. H. (Eds.). (2014). The new landscape of mobile learning: redesigning education in an app-based World. New York: Routledge.

Mnkandla, E., \& Minnaar, A. (2017). The use of social media in e-learning: A metasynthesis. International Review of Research in Open and Distributed Learning, 18(5), 227-248.

O’Rourke, B., \& Stickler, U. (2017). Synchronous communication Technologies for language learning: Promise and challenges in research and pedagogy. CercleS, 7(1), 1-20. doi:10.1515/cercles-2017-0009.

Pavlik, J. V. (2015). Fueling a third paradigm of education: The pedagogical implications of digital, social and mobile media. Contemporary Educational Technology, 6(2), 113-125.

Pimmer, C., Mateescu, M. \& Grohbiel, U. (2016). Mobile and ubiquitous learning in higher education settings. A systematic review of empirical studies. Computers in Human Behavior, 63, 490-501. http://dx.doi.org/10.1016/j.chb.2016.05.057.

Prensky, M. (2006). Listen to the natives. (School should improve teaching). Educational Leadership, 63(4), 8-13.

Rambe, P., \& Bere, A. (2013). Using mobile instant messaging to leverage learner participation and transform pedagogy at a South African University of Technology. British Journal of Educational Technology, 44(4), 544-561. doi:10.1111/bjet.12057.

Rezaei, S., \& Meshkatian, M. (2017). Iranian teachers' attitude towards using social media and technology to increase interaction amongst students inside or outside the classroom. Theory and Practice in Language Studies, 7(6), 419-426. http://dx.doi.org/10.17507/tpls.0706.02.

Robertson, R. (1995). "Glocalization: Time-space and homogeneity-heterogeneity". In M. Featherstone, S. Lash, \& R. Robertson (Eds.). Global Modernities, 25-44.

Samaha, M. \& Hawi, N. (2016). Relationships among smartphone addiction, stress, academic performance, and satisfaction with life. Computers in Human Behavior, 57, 321-325 http://dx.doi.org/10.1016/j. chb.2015.12.045.

Samaie, M., Nejad, A., \& Qaracholloo, M. (2018). An inquiry into the efficiency of WhatsApp for selfand peer-assessments of oral language proficiency. British Journal of Educational Technology, 49(1), 111-126. doi:10.1111/bjet.12519.

Seo, K.. (2013). Using social media effectively in the classroom. Blogs, Wikis, Twitter, and More. Routledge; Taylor and Francis. New York and London.

So, S. (2016). Mobile instant messaging support for teaching and learning in higher education. Internet and Higher Education, 31, 32-42. http://dx.doi.org/10.1016/j.iheduc.2016.06.001.

Stockwell, G., \& Hubbard, P. (2013). Some emerging principles for mobile-assisted language learning. Monterey, CA: The International Research Foundation for English Language Education.

Sundgren, M. (2017). Blurring time and place in higher education with bring your own device applications: a literature review. Education and Information Technologies, 22, 3081-3119. doi: 10.1007/s10639017-9576-3.

Swain, M. (1995). Three fucntions of output in second language learning. In G. Cook \& B. Seidlhofer (Eds.), Principle and practice in applied lingusitics: Studies in honor of H. G. Widdowson (pp. 125144). Oxford: Oxford University Press

Vygotsky, L. S. (1978). Mind in society: The development of higher psychological processes. Cambridge, MA: Harvard University Press.

Wang, C. X, Son, H., Stone, D. E., \& Yan, Q. (2009). Integrating Second Life into an EFL program in China: Research collaboration across the continents. Tech Trends: Linking Research and Practice to Improve Learning, 53(6), 14-19.

Willems, J. \& Bossu, C. (2012). Equity considerations for open educational resources in the glocalization of education. Distance Education, 33(2), 185-199. DOI: 10.1080/01587919.2012.692051.

Yin, R. K. (2014). Case study research: Design and methods (5th ed.). Thousand Oaks, CA: Sage Publications.

You, S., Kim, M., \& Lim, Y. (2016). Value of culturally oriented information design. Universal Access in the Information Society, 15. doi:10.1007/s10209-014-0393-9, 369-391. 